\title{
Surgical Margins and Lymphoid Infiltrate in Cholangiocarcinoma: When a Surgical Technique "Pushes" Tumor Biology to Provide Answer
}

\author{
Guido Torzilli, Luca Viganò
}

Corresponding author:

Guido Torzilli, MD, PhD, FACS

Department of Surgery, Division of

Hepatobiliary \& General Surgery

Humanitas University \& Research

Hospital- IRCCS

Via A. Manzoni, 56 20089, Rozzano

Milano - Italy

Tel: +39-02-8224-4769

Fax: +39-02-8224-4590

E-mail: guido.torilli@hunimed.eu
Received: 20.07.2018

Accepted: 14.08.2018
Department of Hepatobiliary \& General Surgery, Humanitas University \& Research Hospital IRCCS, Humanitas University, Via Manzoni 56, 20089, Rozzano, Milan, Italy

\section{INTRODUCTION}

Mass-forming cholangiocarcinoma (MFCCC) is a disease at increasing incidence $(1,2)$. Liver resection (LR) is the standard treatment, while chemotherapy has a limited effectiveness $(3,4)$. Five-year survival rates after complete surgery range between 20 and 35\% (5-9). Although surgery represents the unique curative treatment, the disease is characterized by low resectability and high post-surgical recurrences rates (1-4). To date, resectability is based on morphological features (number and size of lesions, vascular invasion), lymphnode metastases ( $\mathrm{N}$ stage), and surgical radicality (5-12). If the surgical technique could play a role in improving resectability, molecular markers rather than gross tumor features could aid in defining and clarifying further prognostic predictors helpful to better select and manage the patients accordingly.

On a technical standpoint, the margin width, if negative, does not impact the outcome, while a positive margin $(<1 \mathrm{~mm}, \mathrm{R} 1$ resection) is associated with higher local recurrence rate and worse survival (8-15). However, our group disclosed subcategories of R1 with a different prognostic impact in the event of surgery for colorectal liver metastases, which allowed to increase their resectability (16-17). Whether these subcategories play a role for other liver tumors is still matter of debate.

Prognosis prediction is of paramount relevance for patients management either for their selection, and for the therapeutic and follow up strategies. Reliable molecular markers for MFCCC are still lacking as well as an adequate assessment of tumor biology. The analysis of lymphoid infiltrate (LI) may work in this direction. The oncologic impact of $\mathrm{LI}$ has been analyzed in several tumors. The largest evidences concern colorectal cancers (18-23). Focusing on liver tumors, some data have been reported for HCC and colorectal liver metastases (24-32), while no prior study focused on MFCCC.

These two aspects will be discussed in this review article.

\section{SURGICAL MARGINS}

In surgical oncology, the definition of the adequate surgical margin is of para- 
mount importance influencing both resectability, and type of resection. During the last decades, the adequate width of the surgical margin passed from $10 \mathrm{~mm}$ to 1 $\mathrm{mm}$ (33-35). Although mostly referred to colorectal liver metastases, resection margin less than $1 \mathrm{~mm}$, herein named R1par, was associated with higher local recurrence and worse prognosis (33-35). Several analyses confirmed these data also for MFCCC (8-15). However, some recent studies about colorectal liver metastases denied the negative prognostic impact of R1par resection (36-38). The effectiveness of modern chemotherapy regimens and the adoption of targeted therapies probably contributed to these results, especially in patients with multiple bilobar metastases (3639). This is not the case for MFCCC, for which medical treatments have a limited effectiveness and the quality of surgery is still the main determinant of outcome $(3,4)$.

Our group recently proposed a new type of R1 resection, the R1vasc resection in which the tumor is detached from major intrahepatic vessels $(16,17,40-$ 44). This technique relies on the hypothesis that vessels are a sort of boundary to the tumor diffusion and no margin is required if tumor is detachable. Inversely partial resection or division of hepatic vein (according to the degree of vessel wall involvement) and division of glissonean pedicles is recommended in case of invasion $(17,41-43,45)$. The feasibility and safety of R1vasc resection have been previously reported for colorectal liver metastases $(16,17,40)$, and promising data on HCC are going to be published.

MFCCC is usually diagnosed at an advanced stage as large centrally-located masses and often has wide contact with major intrahepatic vessels. In these conditions, the detachment of MFCCC from vessels could shift to resectability in otherwise unresectable patients (bilateral vascular contact). However, R1vasc resection for MFCCC in our initial experience based on more than 50 patients resulted in a poor local disease control (local recurrence in more than one fourth of patients), similar to that obtained for R1par resection, and largely inferior to RO one (unpublished data). Even survival of the R1vasc group was lower than RO group. The discrepancy between the results of R1vasc resection for colorectal liver metastases and R1vasc resection for MFCCC may have several explanations. First, different diseases have different local aggressiveness. Second, MFCCC are often diagnosed as large masses having a wide contact with intrahepatic vessels which results in more difficult tumor-vessel detachment and higher risk for tumor exposure out of the detachment area (mixed R1vasc-R1par resection). Finally, for patients with MFCCC medical treatments provide a limited contribution to the local disease control $(3,4)$. However, just the latest point paradoxically provides rationale for the R1vasc approach in these patients. Indeed, although R1vasc resection in MFCCC seems having an outcome similar to R1par resection showing higher local recurrence risk and lower survival rate compared to RO resection, it assumes clinical relevance once it becomes the only way for shifting it from surgically unresectable to resectable. This is the case because even a risk of local recurrence of one over four patients could be reasonable if compared with the impairment in patients prognosis associated by the exclusion from the surgical perspective.

\section{LYMPHOID INFILTRATE}

The initial studies of $\mathrm{LI}$ explored its association with the tumor pathology data and TNM stages. In colorectal cancers, Galon et al. demonstrated that $\mathrm{CD} 3+$, $\mathrm{CD} 4+$, and CD8+ infiltrates are inversely associated with microvascular, lymphatic, and perineural infiltration into the tumors (21). Conversely, no association between the $\mathrm{LI}$ and microscopic vascular infiltration was reported for HCC by Sun et al. (26) and for MFCCC in our initial analyses (unpublished data). However, we found an association between the $\mathrm{LI}$ and the MFCCC tumor size (the larger the tumor size, the lower the LI), and an inverse association between the CD8+ infiltrate with $T$ and $\mathrm{N}$ stages. This is in line with similar data reported in colorectal cancer $(20,46)$.

The prognostic impact of $\mathrm{LI}$ is the most relevant issue. In 2011, a meta-analysis considering different tumors reported a prognostic value for $\mathrm{CD} 3+$ and $\mathrm{CD} 8+$ infiltrates (47). Colorectal cancer, patients with high CD3+ and CD8+ tumor infiltrates had superior survival and lower recurrence risk in comparison with patients with low infiltrates (21-23). The survival benefit was reported for every tumor stage (21). These data were the basis for the elaboration of an "immunoscore" (23), i.e., an immunological staging system based on the $\mathrm{CD} 3+$ and $\mathrm{CD} 8+$ presence. In the proposers' opinion, that score could integrate or even replace the TNM staging. For liver tumors, only limited data are available to date. In 2003, Okano et al. suggested an association between the $\mathrm{LI}$ and prognosis in 41 colorectal cancer patients with liver metastases (48). Subsequent analyses in the same disease showed that CD3+ and CD8+ infiltrates have an inverse association with tumor doubling time (49), and a positive association with survival (29, 31 ). The same positive prognostic value of $\mathrm{CD} 3+$ and CD8+ cell infiltrates was described in HCC patients 
$(25,26)$. Due to the consistency of data with those reported for colorectal cancers, some authors proposed an immunoscore for HCC patients as well $(24,26)$. In our exploratory studies in MFCCC, CD3+ and CD8+ infiltrates were associated with a superior prognosis. A large survival advantage was observed when a relevant infiltrate was abundant. Furthermore, CD3+ and CD8+ refined prognosis prediction in $\mathrm{T} 1$ and $\mathrm{N} 1$ tumors. Collectively, these results support the notion that LI could complement TNM staging.

Furthermore, Foxp3+ $T$ regulatory cells have been rarely analysed in previous studies. Data from primary tumors and liver metastases in colorectal cancer are inconsistent (28, 32, 48-51). In our experience it seems that a Foxp3+ infiltrate has a strong negative prognostic impact in MFCCC, being associated with significantly lower 5 year survival rate when is evident (unpublished data). Another potential element of interest would be the macrophages (CD69+) infiltrate. Zhou et al. reported a positive association between macrophages and prognosis in colorectal metastases (52). This does not appear to be the case in MFCCC according with our experience which showed no impact on survival of the macrophages infiltrate. Finally, some recent papers investigated the prognostic impact of circulating neutrophils (neu), lymphocytes (lymph) and platelets (PLT), and their ratios. In MFCCC patients, neu/lymph and PLT/lymph ratios have been associated with survival (53-56). However, we are not having confirmatory results in this sense, since neu/lymph and the PLT/lymph seem associated neither with $\mathrm{LI}$ at pathology nor with prognosis. The $\mathrm{LI}$ at pathology and not the ratios of circulating cells acts as prognosticator.

Finally, in colorectal cancer, the analysis of the $\mathrm{LI}$ at the tumor margin together versus the intratumoral $\mathrm{LI}$ improved prognosis prediction (23), but this was not confirmed in studies in liver tumors $(24,25,30)$. Our current experience although based only on data from a limited number of patients, provides some preliminary evidence concerning the prognostic value of intratumoral LI. These should be the starting point for further analyses in larger studies in MFCCC, which should also investigate to the $\mathrm{Ll}$ at the tumor margin.

\section{CONCLUSIONS}

MFCCC was confirmed as a rather aggressive disease since the R1vasc approach is clearly not as successful as for colorectal liver metastases or the HCC. However, considering that surgery still remains the only potentially curative treatment for this tumor, R1vasc surgery in case of otherwise unresectability should be an option to be considered. To better foresee for which patient this policy could be more or less appropriate, markers of tumor biology could potentially be very helpful. Thus, there is renewed interest in studying potential pathological prognostic factors for MFCCC. The intratumoral LI showed preliminary association with patients' prognosis, and could potentially be useful to estimate the post-surgical risk of recurrence. This could aid the surgeons in retailing their surgical attitude accordingly. While the data on intratumoral $\mathrm{LI}$ is validated in larger studies, there is growing interest in evaluating the peritumoral LI which could provide additional prognostic or predictive information for the risk of tumor recurrence after vascular detachment.

\section{Conflicts of Interest}

No conflicts of interest were declared.

\section{REFERENCES}

1. Shaib YH1, Davila JA, McGlynn K, El-Serag HB. Rising incidence of intrahepatic cholangiocarcinoma in the United States: a true increase? J Hepatol. 2004;40(3):472-7.

2. Khan SA, Toledano MB, Taylor-Robinson SD. Epidemiology, risk factors, and pathogenesis of cholangiocarcinoma. HPB (Oxford). 2008;10(2):77-82.

3. Ebata T, Ercolani G, Alvaro D, Ribero D, Di Tommaso L, Valle JW. Current Status on Cholangiocarcinoma and Gallbladder Cancer. Liver Cancer. 2016;6(1):59-65.

4. Banales JM, Cardinale V, Carpino G, Marzioni M, Andersen JB, Invernizzi $P$, et al. Expert consensus document:. Cholangiocarcinoma: current knowledge and future perspectives. Consensus statement from the European Network for the Study of Cholangiocarcinoma (ENS-CCA). Nat Rev Gastroenterol Hepatol. 2016;13(5):261-80.

5. de Jong MC, Nathan H, Sotiropoulos GC, Paul A, Alexandrescu S, Marques $\mathrm{H}$, et al. Intrahepatic cholangiocarcinoma: an international multi-institutional analysis of prognostic factors and lymph node assessment. J Clin Oncol. 2011;29(23):3140-5.

6. Kim Y, Moris DP, Zhang XF, Bagante F, Spolverato G, Schmidt C, et al. Evaluation of the 8th edition American Joint Commission on Cancer (AJCC) staging system for patients with intrahepatic cholangiocarcinoma: A surveillance, epidemiology, and end results (SEER) analysis. J Surg Oncol. 2017;116(6):643-650.

7. Si A, Li J, Xiang H, Zhang S, Bai S, Yang P, et al. Actual over 10-year survival after liver resection for patients with intrahepatic cholangiocarcinoma. Oncotarget. 2017;8(27):44521-44532.

8. Farges D, Fuks D, Boleslawski E, Le Treut YP, Castaing D, Laurent A, et al. Influence of surgical margins on outcome in patients with intrahepatic cholangiocarcinoma: a multicenter study by the AFC-IHCC2009 study group. Ann Surg. 2011;254(5):824-29.

9. Ribero D, Pinna AD, Guglielmi A, Ponti A, Nuzzo G, Giulini SM, et al. Surgical Approach for Long-term Survival of Patients With Intrahepatic Cholangiocarcinoma: A Multi-institutional Analysis of 434 Patients. Arch Surg. 2012 Dec;147(12):1107-13.

10. Tamandl D, Herberger B, Gruenberger B, Puhalla H, Klinger M, Gruenberger T. Influence of hepatic resection margin on recurrence and survival in intrahepatic cholangiocarcinoma. Ann Surg Oncol. 2008;15(10):2787-94.

11. Tang H, Lu W, Li B, Meng X, Dong J. Influence of surgical margins on overall survival after resection of intrahepatic cholangiocarcinoma: A meta-analysis. Medicine (Baltimore). 2016 Aug;95(35):e4621.

12. Guglielmi A, Ruzzenente A, Campagnaro T, Pachera S, Valdegamberi A, Nicoli $P$, et al. Intrahepatic cholangiocarcinoma: prognostic factors after surgical resection. World J Surg. 2009;33(6):1247-54.

13. Spolverato G, Yakoob MY, Kim Y, Alexandrescu S, Marques HP, Lamelas J. The Impact of Surgical Margin Status on Long-Term Outcome After Resection for Intrahepatic Cholangiocarcinoma. Ann Surg Oncol. 2015;22(12):4020-8. 
14. Li MX, Bi XY, Li ZY, Huang Z, Han Y, Zhao JJ, et al. Impaction of surgical margin status on the survival outcome after surgical resection of intrahepatic cholangiocarcinoma: a systematic review and meta-analysis. J Surg Res. 2016; 203(1):163-73.

15. Shimada K, Sano T, Sakamoto Y, Esaki M, Kosuge T, Ojima H. Clinical impact of the surgical margin status in hepatectomy for solitary mass-forming type intrahepatic cholangiocarcinoma without lymph node metastases. J Surg Oncol. 2007;96(2):160-5.

16. Viganò L, Procopio F, Cimino MM, Donadon M, Gatti A, Costa G, et al. Is Tumor Detachment from Vascular Structures Equivalent to R0 Resection in Surgery for Colorectal Liver Metastases? An observational cohort. Ann Surg Oncol. 2016;23(4):1352-60.

17. Torzilli G, Procopio F, Viganò $L$ et al. Hepatic vein management in a parenchyma-sparing policy for resecting colorectal liver metastases at the caval confluence. Surgery. In press.

18. Holcombe RF, Jacobson J, Dakhil SR, Stewart RM, Betzing KS, Kannan K, et al. Association of immune parameters with clinical outcome in stage III colon cancer: results of Southwest Oncology Group Protocol 9009. Cancer Immunol Immunother. 1999;48(9): 533-9.

19. Naito Y, Saito K, Shiiba K, Ohuchi A, Saigenji K, Nagura H, et al. CD8+ $T$ cells infiltrated within cancer cell nests as a prognostic factor in human colorectal cancer. Cancer Res. 1998;58(16):3491-4.

20. Pagès F1, Berger A, Camus M, Sanchez-Cabo F, Costes A, Molidor R, et al. Effector memory T cells, early metastasis, and survival in colorectal cancer. N Engl J Med. 2005;353(25):2654-66.

21. Galon J, Costes A, Sanchez-Cabo F, Kirilovsky A, Mlecnik B, LagorcePagès $C$, et al. Type, density, and location of immune cells within human colorectal tumors predict clinical outcome. Science. 2006;313(5795):1960-4.

22. Pagès F, Kirilovsky A, Mlecnik $B$, Asslaber M, Tosolini M, Bindea G, et al. In situ cytotoxic and memory $T$ cells predict outcome in patients with early-stage colorectal cancer. J Clin Oncol. 2009:27(35):5944-51.

23. Galon J, Pagès F, Marincola FM, Angell HK, Thurin M, Lugli A, et al. Cancer classification using the Immunoscore: a worldwide task force. J Transl Med. 2012;10:205

24. Yao Q1, Bao X, Xue R, Liu H, Liu H, Li J, et al. Prognostic value of immunoscore to identify mortality outcomes in adults with HBV-related primary hepatocellular carcinoma. Medicine (Baltimore). 2017:96(17):e6735.

25. Gabrielson A, Wu Y, Wang H, Jiang J, Kallakury B, Gatalica Z, et al. Intratumoral CD3 and CD8 T-cell Densities Associated with RelapseFree Survival in HCC. Cancer Immunol Res. 2016:4(5):419-30.

26. Sun C, Xu J, Song J, Liu C, Wang J, Weng C, et al. The predictive value of centre tumour $\mathrm{CD8}^{+} \mathrm{T}$ cells in patients with hepatocellular carcinoma: comparison with Immunoscore. Oncotarget. 2015; 6(34):35602-15.

27. Okano K, Maeba T, Moroguchi A, Ishimura K, Karasawa Y, Izuishi K, et al. Lymphocytic infiltration surrounding liver metastases from colorectal cancer. J Surg Oncol. 2003;82(1):28-33.

28. Halama N, Spille A, Lerchl T, Brand K, Herpel E, Welte S, et al. Hepatic metastases of colorectal cancer are rather homogeneous but differ from primary lesions in terms of immune cell infiltration. Oncoimmunology. 2013;2(4):e24116.

29. Halama N, Michel S, Kloor M, Zoernig I, Benner A, Spille A, et al. Localization and density of immune cells in the invasive margin of human colorectal cancer liver metastases are prognostic for response to chemotherapy. Cancer Res. 2011:71(17):5670-7.

30. Wagner P, Koch M, Nummer D, Palm S, Galindo L, Autenrieth D, et al. Detection and functional analysis of tumor infiltrating T-lymphocytes (TIL) in liver metastases from colorectal cancer. Ann Surg Oncol. 2008;15(8):2310-7.

31. Katz SC1, Pillarisetty V, Bamboat ZM, Shia J, Hedvat C, Gonen M, et al. $T$ cell infiltrate predicts long-term survival following resection of colorectal cancer liver metastases. Ann Surg Oncol. 2009;16(9): 2524-30.

32. Donadon M, Hudspeth K, Cimino M, Di Tommaso L, Preti M, Tentorio $P$, et al. Increased Infiltration of Natural Killer and T Cells in Colorectal Liver Metastases Improves Patient Overall Survival. J Gastrointest Surg. 2017;21(8):1226-1236.

33. Poon RT, Fan ST, Ng IO, Wong J. Significance of resection margin in hepatectomy for hepatocellular carcinoma: A critical reappraisal. Ann Surg. 2000;231(4):544-51.

34. Hamady ZZ, Lodge JP, Welsh FK, Toogood GJ, White A, John T, et al. One-millimeter cancer-free margin is curative for colorectal liver metastases: a propensity score case-match approach. Ann Surg. 2014;259(3):543-8

35. Pawlik TM, Scoggins CR, Zorzi D, Abdalla EK, Andres A, Eng C, et al. Effect of surgical margin status on survival and site of recurrence after hepatic resection for colorectal metastases. Ann Surg. 2005;241(5):715-22, discussion 722-4.

36 de Haas RJ, Wicherts DA, Flores E, Azoulay D, Castaing D, Adam R. $\mathrm{R} 1$ resection by necessity for colorectal liver metastases: is it still a contraindication to surgery? Ann Surg. 2008;248(4):626-37.

37. Ayez N, Lalmahomed ZS, Eggermont AM, ljzermans JN, de Jonge J, van Montfort K, et al. Outcome of microscopic incomplete resection (R1) of colorectal liver metastases in the era of neoadjuvant chemotherapy. Ann Surg Oncol. 2012;19(5):1618-27.

38. Eveno C, Karoui M, Gayat E, Luciani A, Auriault ML, Kluger MD, et al. Liver resection for colorectal liver metastases with peri-operative chemotherapy: oncological results of R1 resections. HPB (Oxford). 2013;15(5):359-64.

39. Andreou A, Aloia TA, Brouquet A, Dickson PV, Zimmitti G, Maru DM, et al. Margin status remains an important determinant of survival after surgical resection of colorectal liver metastases in the era of modern chemotherapy. Ann Surg. 2013;257(6):1079-88.

40 Torzilli G, Donadon M, Palmisano A, Marconi M, Procopio F, Botea F et al. Ultrasound guided liver resection: does this approach limit the need for portal vein embolization? Hepatogastroenterology. 2009:56(94-95):1483-90.

41. Torzilli G, Montorsi M, Donadon M, Palmisano A, Del Fabbro D, Gambetti $A$ et al. "Radical but conservative" is the main goal for ultrasonography-guided liver resection: prospective validation of this approach. J Am Coll Surg. 2005; 201(4):517-28.

42. Torzilli G, Procopio F, Costa G. Adjuncts to hepatic resection - ultrasound and emerging guidance systems. In: Jarnagin WR, ed. Blumgart's Surgery of the Liver, Pancreas, and Biliary Tract. 6th ed. Elsevier Saunders, 2016.

43. Torzilli G. Ultrasond-guided liver surgery. An atlas. 1st ed. Springer, 2014.

44. Torzilli G, Procopio F, Viganò L, Costa G, Fontana A, Cimino M, et al. The Liver Tunnel: intention-to-treat validation of a new type of hepatectomy. Ann Surg. 2017 Sep 11.

45. Torzilli G, Viganò L, Gatti A, Costa G, Cimino M, Procopio F, et al. Twelve-year experience of "radical but conservative" liver surgery for colorectal metastases: impact on surgical practice and oncologic efficacy. HPB (Oxford). 2017; 19(9):775-784.

46. Laghi L, Bianchi P, Miranda E, Balladore E, Pacetti V, Grizzi F, et al. CD3+ cells at the invasive margin of deeply invading (pT3-T4) colorectal cancer and risk of post-surgical metastasis: a longitudinal study. Lancet Oncol. 2009;10(9):877-84.

47. Gooden MJ, de Bock GH, Leffers N, Daemen T, Nijman HW. The prognostic influence of tumour-infiltrating lymphocytes in cancer: a systematic review with meta-analysis. $\mathrm{Br} \mathrm{J}$ Cancer. 2011;105(1):93-103.

48. Okano K, Maeba T, Moroguchi A, Ishimura K, Karasawa Y, Izuishi K, et al. Lymphocytic infiltration surrounding liver metastases from colorectal cancer. J Surg Oncol. 2003;82(1):28-33.

49. Kito A, Tanaka K, Fujimaki H, Nakazawa M, Togo S, Minami M, et al. Tumor doubling time and local immune response to hepatic metastases from colorectal cancer. J Surg Oncol. 2007;96(6):525-33.

50. Suzuki H, Chikazawa N, Tasaka T, Wada J, Yamasaki A, Kitaura Y, et al. Intratumoral CD8(+) T/FOXP3 (+) cell ratio is a predictive marker for survival in patients with colorectal cancer. Cancer Immunol Immunother. 2010;59(5):653-61.

51. Salama P, Phillips M, Grieu F, Morris M, Zeps N, Joseph D, et al. Tumor-infiltrating FOXP3+ T regulatory cells show strong prognostic significance in colorectal cancer. J Clin Oncol. 2009; 27(2):186-92.

52. Zhou $Q$, Peng RQ, Wu XJ, Xia Q, Hou JH, Ding Y, et al. The density of macrophages in the invasive front is inversely correlated to liver metastasis in colon cancer. J Transl Med. 2010:8:13.

53. Omichi K, Cloyd JM, Yamashita S, Tzeng CD, Conrad C, Chun YS, et al. Neutrophil-to-lymphocyte ratio predicts prognosis after neoadjuvant chemotherapy and resection of intrahepatic cholangiocarcinoma. Surgery. 2017 0ct;162(4):752-765

54. Lin G, Liu Y, Li S, Mao Y, Wang J, Shuang Z, et al. Elevated neutrophil-to-lymphocyte ratio is an independent poor prognostic factor in patients with intrahepatic cholangiocarcinoma. Oncotarget. 2016;7(32):50963-50971.

55. Chen Q, Dai Z, Yin D, Yang LX, Wang Z, Xiao YS, et al. Negative impact of preoperative platelet-lymphocyte ratio on outcome after hepatic resection for intrahepatic cholangiocarcinoma. Medicine (Baltimore) 2015:94(13):e574.

56. Xue TC, Zhang L, Xie XY, Ge NL, Li LX, Zhang BH, et al. Prognostic significance of the neutrophil-to-lymphocyte ratio in primary liver cancer: a meta-analysis. PLoS One. 2014;9(5):e96072. 